\title{
An experimental investigation of flow boiling heat transfer of R-141b and R-1234yf in microchannels
}

\author{
Alisher Shamirzaev ${ }^{*}$ \\ Kutateladze Institute of Thermophysics SB RAS, 630090 Novosibirsk, Russia
}

\begin{abstract}
This study presents experimental results of flow boiling heat transfer of refrigerants R-141b and R-1234yf in a horizontal microchannel heat sink. The copper microchannel heat sink contains 21 microchannels with $335 \times 930 \mu \mathrm{m}$ cross-section. Distribution of local heat transfer coefficients along the length and width of the microchannel plate were measured in the range of external heat fluxes from 50 to $550 \mathrm{~kW} / \mathrm{m}^{2}$. Finally, comparisons with predictions according to the model of flow boiling heat transfer are reported for the data sets.
\end{abstract}

\section{Introduction}

Studies of the processes of heat and mass transfer in microsystems with phase transformations are the fast-developing field of science. This is due to the growth of technological applications, which require the transfer of large heat and mass flows in a limited volume, including compact steam generators/condensers of power and cryogenic devices, microprocessor cooling systems [1]. At channel size reduction, a wide variety of the phenomena arise which are not typical for conventional tubes. That confirmed by experimental data from [2-6] and other papers. In despite of a large number of published methods for predicting heat transfer in microchannels, the application of these methods requires verification, and the determination of heat transfer for various heat transfer modes in boiling in microchannels, as noted in [7], remains actual. The objective of this study is to experimentally establish how the local flow boiling heat transfer coefficient correlates with the heat flux, mass flux and vapor quality.

\section{Experimental equipment and methods}

Figure 1 shows the setup for investigation of refrigerants flow boiling heat transfer in the microchannel heat sink. Liquid refrigerant is supplied from the cooler through the filter and flow controller Bronkhorst HI-TECH to the temperature control system via the pump. Then the refrigerant goes through the pre-evaporator to achieve the flow with desired vapor quality. After passing through to the microchannel heat sink it goes to the condenser.

* Corresponding author: alisham@ngs.ru 


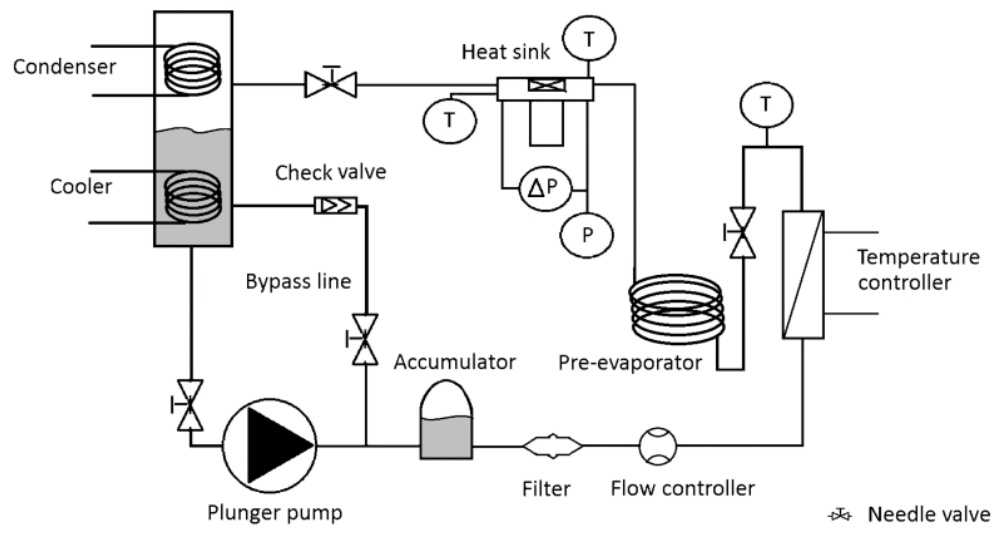

Fig. 1. Schematic of the experimental setup.

Twenty-one microchannels were made by precise milling of $335 \mu \mathrm{m}$ wide and $930 \mu \mathrm{m}$ deep micro-slots into the $20 \times 40 \mathrm{~mm}$ top surface of the oxygen-free copper plate of the microchannel heat sink. The distance between channels equals to $650 \mu \mathrm{m}$ (fin thickness) at total plate thickness of $2.5 \mathrm{~mm}$. Wall roughness Ra was estimated at $1 \mu \mathrm{m}$, using surface measurement by an optic microscope. The microchannel plate and heating block were mounted in the stainless steel container with two sections, divided by the partition wall for the local heat flux measurements, see fig. 2. The thickness of the partition wall equaled 2.51 $\mathrm{mm}$. Tin gaskets with $0.5 \mathrm{~mm}$ thickness and thermocouples inside were placed between the microchannel plate and partition wall as far as between the heating block and the partition wall. Gaskets were melted during the assembly process to reduce the contact thermal resistance. After mounting, the microchannel plate was closed by the copper cover and soldered.

Heat was supplied to the test section by means of the copper block with mounted heat cartridges, which can supply the heat flux up to $550 \mathrm{~kW} / \mathrm{m}^{2}$. During the test, temperatures of tin gaskets were measured in four cross-sections along the heat sink at distances of 5 $\mathrm{mm}, 15 \mathrm{~mm}, 25 \mathrm{~mm}$, and $35 \mathrm{~mm}$ from the microchannels inlet, see fig.2. The numerical calculations were performed to obtain actual temperatures of the internal channel wall and temperature difference on the partition wall. Due to small fin height and high thermal conductivity of copper the temperature of the internal channel wall was almost uniform in the cross-section.

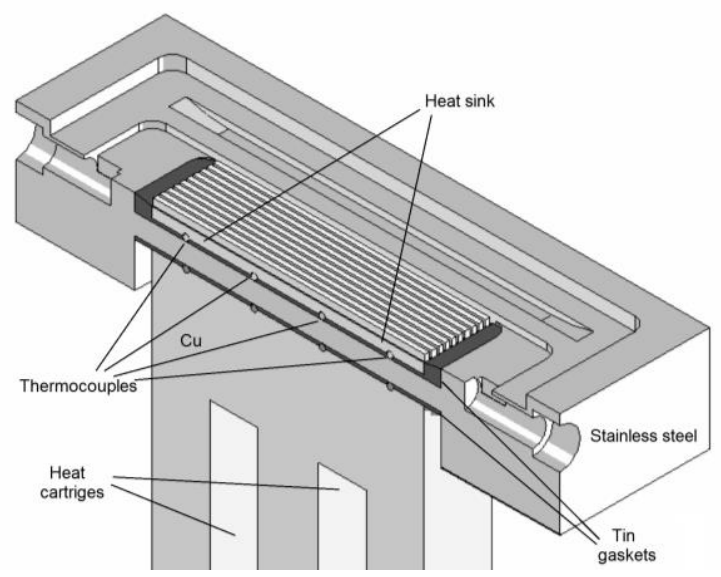

Fig. 2. Schematic of the test section. 
In each cross-section, two thermocouples were placed along the width of the microchannel plate. It allowed controlling the even flow distribution in the microchannel plate. To manage flow maldistribution the inlet and outlet ports were connected to the microchannel plate through inlet and outlet constrictions, see fig. 2. Pressures and temperatures in the inlet and outlet restrictions were measured using the pressure probes and insulated thermocouples. The heat losses from the test section were calibrated and did not exceed $0.19 \mathrm{~W} / \mathrm{K}$. The liquid flow rate was measured by the flow controller with accuracy of $0.02 \mathrm{~g} / \mathrm{s}$.

The heat transfer coefficient was calculated using internal wall temperatures $T_{w, i}$ :

$$
h_{i}=q_{w, i} /\left(T_{w, i}-T_{\text {sat }, i}\right)
$$

where $T_{s a t, i}$ is the saturation temperature related to the $i$-th thermocouple and $q_{w, i}$ is the local heat flux from the inner wall to the flow. The saturation temperature related to the $i$-th thermocouple was determined using linear approximation of the measured input and output pressure and the dependence of the saturation temperature on pressure for the tested refrigerant. Local heat flux was determined from temperature difference $\Delta T_{w, i}$ through the partition wall as follows:

$$
q_{w, i}^{*}=\left(\frac{\delta_{s t}}{\lambda_{s t}}+\frac{\delta_{t i n}}{\lambda_{t i n}}\right)^{-1} \Delta T_{w, i}, \quad q_{w, i}=q_{w, i}^{*} \frac{A_{h s}}{A_{i n}}
$$

Here, $q_{w, i}^{*}$ is the external local heat flux, $\lambda_{s t}$ and $\lambda_{\text {tin }}$ are thermal conductivities of stainless steel and tin, respectively, $\delta_{s t}$ and $\delta_{t i n}$ are thicknesses of the partition wall and tin gasket, $A_{h s}$ is the external area of heat sink, and $A_{i n}$ is the inner area of heat sink. The vapour quality at the heat sink inlet was determined considering heat production in the pre-evaporator $Q_{\text {coil }}$ and liquid temperature at the pre-evaporator inlet $T_{0}$ as follows:

$$
x_{0}=\left[Q_{\text {coil }}-Q_{\text {lost }, \text { coil }}-m \cdot C_{p, i q}\left(T_{\text {sat,in }}-T_{0}\right)\right] /\left(m h_{f g}\right)
$$

where $m$ is the mass flow rate, $h_{f g}$ is the latent heat of vaporization, and $C_{p, l i q}$ is the specific heat of liquid. The vapor quality along the heat sink was calculated as follows:

$$
x_{L_{i}}=x_{0}+\left(\int_{0}^{L_{i}} W\left\langle q_{\mathrm{w}}\right\rangle d L-Q_{\text {lost }, h s} l_{i} / L_{h s}\right)\left(\dot{m} \cdot h_{f g}\right),
$$

where $L_{\mathrm{hs}}$ is the heat sink length, $Q_{\text {lost hs }}$ is the heat loss, $W$ is the heat sink width, $\left\langle q_{w}\right\rangle$ is the cross section averaged local heat flux supplied to heat sink, and $x_{0}$ is vapor quality at the heat sink inlet.

We have verified the measurement procedure using tests on measuring the heat transfer coefficient distribution along the heat sink length at subcooled refrigerant flowing. The data from single-phase experiments, taking into account the initial section, were in good agreement with the data from [8].

\section{Flow boiling data}

For both investigated refrigerants, the dependences of heat fluxes on wall overheating for fixed pressure and mass flow have been obtained. The comparisons of experimental data with pool boiling correlation and prediction by [9] are presented on fig. 3. In all experimental data from fig. 3 the initial vapor quality was changed for the local vapor quality in the point of measurement 


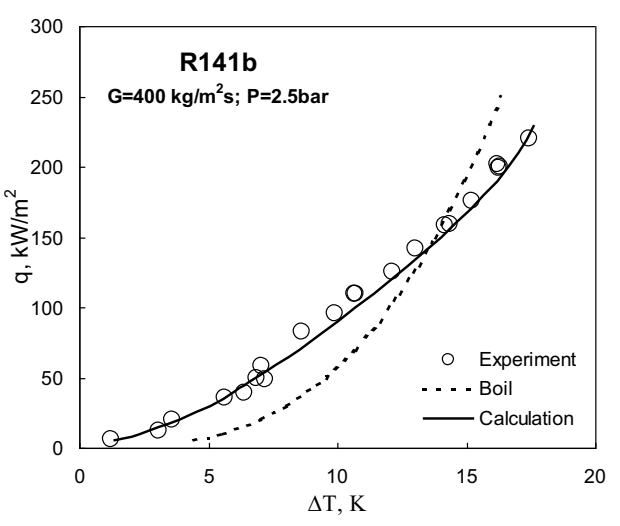

a

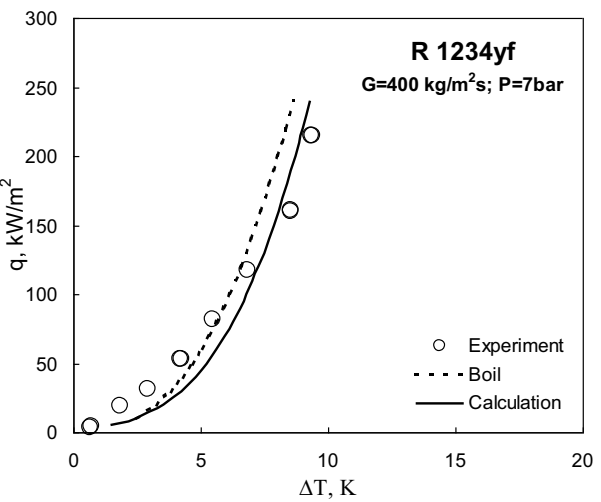

b

Fig. 3. Dependence of heat flux from overheating: (a) for R141b; (b) for R1234yf.

to be in range from 0.15 to 0.3 . According to [10] Cooper correlation [11] was used to calculate R141b pool boiling (dotted lines fig. 3a). For calculation of R1234yf pool boiling the correlation [6] was used (dotted lines fig. 3b). The corresponding correlations for pool boiling were used to calculate flow boiling heat transfer with [3] (solid line fig.3). At the considered conditions, the measured flow boiling heat transfer coefficients exceeded pool boiling prediction when local heat flux was less than $100 \mathrm{~kW} / \mathrm{m}^{2}$ and were in good agreement with prediction by [3] in all investigated range of heat fluxes.

This work was supported by RFBR grant 15-08-07506-a.

\section{References}

1. V. Kuznetsov, J. Phys.: Conf. Ser. 754, 032012 (2016)

2. V.V. Kuznetsov, A.S. Shamirzaev, Heat Transfer Eng. 28, 738 (2007)

3. V.V. Kuznetsov, A.S. Shamirzaev, Microgravity Sci. Tech. 21, 305 (2009)

4. V.V. Kuznetsov, A.S. Shamirzaev, I.A. Kozulin, S.P. Kozlov, Heat Transfer Engineering 34, 235 (2013)

5. V. V. Kuznetsov, S. V. Dimov, P. A. Houghton, A. S. Shamirzaev, S. Sunder, Proc. 1st Int. Conf. on Microchannels and Minichannels. ASME, 683 (2003)

6. V.V. Kuznetsov, et al. J. of Phys.: Conf. Series 395, 012093 (2012)

7. S.S. Bertsch, E.A Groll, S.V. Garimella, Int. J. Heat Mass Transfer 52, 2110 (2009)

8. R.J. Phillips, Forced-Convection, Liquid-Cooled, Microchannel Heat Sinks, / Technical rept. Massachusetts Inst. of Tech., Lexington Lincoln Lab, (1988)

9. V.V. Kuznetsov, A.S. Shamirzaev, Heat Transfer Eng. 37, 1105 (2016)

10. V. Trisaksri, S. Wongwises, Int. J. of Heat and Mass Transfer 52, 1582 (2009)

11. M.G. Cooper, 1st UK Natl. Heat Transfer Conf. (I. Chem. E. Symp. series No. 86) 2 785 (1984)

12. D. Jung, H. Lee, D. Bae, and S. Oho, Int. J. Refrig. 27, 409 (2004) 